\title{
Balance de la participación electoral indígena en Ecuador: 1996-2013
}

\section{Evaluation of Electoral Participation of Indigenous Peoples in Ecuador: 1996-2013}

Fernando García

Recepción: 21 de junio de 2013

Aceptación: 29 de julio de 2013

\section{Resumen}

El artículo revisa el desempeño del Movimiento de Unidad Plurinacional Pachakutik a lo largo de trece procesos electorales llevados a cabo entre los ańos 1996 al 2013, por medio de los cuales se eligieron presidentes y vicepresidentes, diputados, asambleístas, funcionarios de gobiernos locales y se llevaron a cabo tres consultas populares. Se muestra los efectos positivos y negativos de su participación en la esfera política nacional y los retos que deberá enfrentar a futuro.

Palabras clave: Pachakutik, movimiento indígena, participación electoral, elecciones, Ecuador.

Abstract

This article looks at the development of the Packakutik Plurinational Unity Movement throughout thirteen electoral processes which took place from 1996 to 2013. In these elections, presidents, vice presidents, members of congress, assembly members, and local government officials were elected. Three referendums were also held. Both the positive and negative effects of this movement's participation in the national political sphere and the challenges it will face in the future are presented.

Keywords: Pachakutik, indigenous movement, electoral turnout, elections, Ecuador. 


\section{Introducción}

T uego de cumplirse diecisiete años de la participación del Movimiento de Unidad Plurinacional Pachakutik, brazo electoral ${ }^{1}$ de la Confederación de Nacionalidades Indígenas del Ecuador (CONAIE) en las lides electorales, se hace indispensable hacer un balance de su accionar en la vida política y democrática del país.

El presente artículo pretende revisar el desempeńo de Pachakutik a lo largo de trece procesos electorales ${ }^{2}$ llevados a cabo entre los años 1996 al 2013, por medio de los cuales se eligieron presidentes y vicepresidentes, diputados, asambleístas, funcionarios de gobiernos locales y se llevaron a cabo tres consultas populares.

La primera parte estará dedicada a revisar el desempeño electoral de Pachakutik durante el periodo mencionado, para luego analizar la relación que el movimiento social indígena ha mantenido con el movimiento electoral indígena en las diferentes coyunturas políticas atravesadas, y finalmente concluir con algunas reflexiones sobre el futuro del Movimiento de Unidad Plurinacional Pachakutik en la escena política nacional.

\section{Revisando el desempeño electoral de Pachakutik}

Uno de los impedimentos más importantes para la vigencia plena de la democracia en el Ecuador y en los países de la región andina es la escasa calidad de la representación política. La población votante y los nuevos movimientos sociales aparecen desconectados de las instituciones políticas en general y de los partidos políticos en especial, ninguno ha sido capaz de responder a las necesidades básicas insatisfechas de la sociedad

1 Prefiero hablar de brazo electoral del movimiento social antes que brazo político, ya que el mismo movimiento social, al ser tal, es político.

2 Los procesos son los siguientes: 1996 (presidente, diputados y gobiernos locales), 1997 (asambleístas), 1998 (presidente y diputados), 2000 (gobiernos locales), 2002 (presidente y diputados), 2004 (gobiernos locales), 2006 (presidente y diputados), 2007 (consulta popular convocatoria a Asamblea), 2007 (asambleístas), 2008 (consulta popular para aprobación de la Constitución), 2009 (presidente, asambleístas y gobiernos locales), 2011 (consulta popular reforma de la justicia) y 2013 (elecciones presidenciales y legislativas). 
y de representar las identidades colectivas surgidas al interior de cada Estado-nación ${ }^{3}$.

Adicionalmente, la crisis de representación política ha ido acompañada de una de las crisis más agudas de las economías nacionales, caracterizada por fenómenos como la hiperinflación, la dolarización, el desempleo y subempleo, el pago de la deuda externa, la privatización de las empresas de servicios públicos, la presencia de empresas transnacionales, las medidas de ajuste, la inmigración internacional, etc. Todos estos factores han llevado a un proceso incontenible de empobrecimiento de la población y al surgimiento de movilizaciones populares caracterizadas por algunos autores como formas de desobediencia civil.

Otro impedimento importante para la práctica de la democracia constituye la pérdida cada vez más acelerada de los valores éticos y morales, los escándalos de corrupción que no solamente son interminables sino que la mayoría quedan en la impunidad. La credibilidad de las autoridades electas ante el ciudadano común termina apenas finalizan las campańas electorales. La participación ciudadana no puede reducirse al ejercicio de votar; se debería exigir el cumplimiento del mandato ofrecido en las campañas, así como la rendición de cuentas periódicas e inclusive la revocatoria de los funcionarios que no cumplan con lo ofrecido.

Los elementos mencionados han llevado a un rechazo de la política, de los políticos y a la exigencia de una nueva forma de hacer política utilizando inclusive un discurso antipolítico. En este sentido, el movimiento indígena ecuatoriano, cuando se convierte en actor político, como una de las primeras reivindicaciones que planteó fue la necesidad de la reforma del sistema político (CONAIE, 1994), este proceso que se encuentra en ciernes en el país ha tenido sus avances y retrocesos y también sus condicionamientos.

3 Sobre el quiebre del sistema de partidos en Perú y Venezuela y su fragmentación en Ecuador y Bolivia se recomienda ver: Burbano (2004); Dietz y Myers (2001); Freidenberg y Alcántara (2001); Levitsky y Cameron (2001); Mainwaring y Schully (1995); Mejía (2002); Pachano (1998); Roberts (2002); Romero (1994); Rospigliosi (1995); Tanaka (1998) y Whitehead (2001). 
Algunas condiciones permitieron la creación de un mecanismo electoral favorable para el movimiento indígena. Antes, es importante puntualizar que este proceso se ha dado en el marco del retorno a la democracia en 1979 y su posterior mantenimiento. A pesar de la crisis política mencionada y de los obstáculos reseñados, durante más de treinta ańos, la democracia ecuatoriana ha sobrevivido aunque haya sido a saltos y a brincos.

Una primera condición fue aprobada por el Congreso Nacional en 1979 cuando permitió el voto de los analfabetos, de los cuales un alto porcentaje está constituido por población indígena $a^{4}$. La segunda se produce en 1994, año en que el mismo Congreso autorizó el reconocimiento de los movimientos políticos independientes para participar en las elecciones de votación popular, con lo cual los partidos políticos tradicionales perdieron el monopolio de la representación política. Este hecho de singular importancia le va a permitir al movimiento indígena, y a otros movimientos nacionales y locales, participar en las elecciones con candidatos propios 5 . La otra cara de la moneda de esta resolución fue la proliferación y fragmentación de partidos y movimientos que muestra el país, así por ejemplo en el periodo 1979-1997 alcanzaron la suma de veintidós y, según el nuevo Consejo Nacional Electoral, para las elecciones de 2009 se inscribieron cincuenta y seis organizaciones políticas, nueve partidos y cuarenta y siete movimientos.

La tercera condición estuvo relacionada con el plebiscito que el Presidente Durán Ballén convocó en 1995 para aprobar una propuesta de reformas neoliberales, la cual fue rechazada mayoritariamente en las urnas, en gran parte debido a la campańa en contra que fue liderada por la CONAIE donde mostraron gran poder de convocatoria y apoyo popular.

4 Según el Censo de 2010 la tasa nacional de analfabetismo es todavía del 6,8\%. Para el caso de los pueblos indígenas sube al 20,4\% (del total de hombres analfabetos a nivel nacional el 13,7\% son hombres indígenas y del total de mujeres analfabetas a nivel nacional el $26,7 \%$ son mujeres indígenas).

5 Medidas similares fueron aprobadas en Colombia en 1991, en Venezuela en 1998 y en Bolivia en 2004 . 
Otra condición importante del proceso fue la inestabilidad y debilidad del sistema político ecuatoriano en general y de los partidos en especial. En este sentido la propuesta del movimiento indígena se presenta como alternativa al combinar las demandas anti neoliberales y contra hegemónicas con las étnico culturales. El movimiento, desde su creación en 1996, planteó la conformación de un nuevo tipo de Estado, distinto al Estado neoliberal vigente. Esa propuesta descansaba en la posibilidad del movimiento de crear su "propia institucionalidad" (Díaz-Polanco y Sánchez, 2002). Sin embargo, luego del IV Congreso de CONAIE realizado en 1993 en el cual se aprobó el proyecto político, la causa de la movilización cambió y se convirtió en la construcción del Estado plurinacional y de una sociedad intercultural entendida como la interrelación entre las diversas culturas de los pueblos que habitan en un mismo espacio geopolítico, basada en el respeto a las diferencias culturales y en el logro de la unidad en la diversidad (García, 2001).

En la década de 1990 un conjunto de factores van a confluir para que se inicie en los países andinos un importante proceso de reformas constitucionales. Por un lado, la demanda de una mayor participación y representatividad por parte de los movimientos sociales y, por otro, los esfuerzos de la élite política por potenciar la legitimidad y la gobernabilidad de las instituciones estatales. En Ecuador, la Asamblea Nacional Constituyente de 1998 y de 2008 incorporaron reformas inspiradas en el derecho internacional, los organismos multilaterales de desarrollo y otras constituciones latinoamericanas. Las principales fueron: el reconocimiento explícito como nacionalidades y pueblos al aprobar el carácter plurinacional e intercultural del Estado ecuatoriano; el reconocimiento de los sistemas jurídicos indígenas, en otras palabras, la vigencia del pluralismo jurídico; el reconocimiento de veintiún derechos colectivos sobre temas como discriminación racial, consulta previa, libre e informada, territorios colectivos, educación bilingüe intercultural, identidad, autoridades propias, etc.

Además del reconocimiento constitucional alcanzado, el movimiento indígena logró el derecho de ocupar cargos públicos y ejercer cierta autonomía política y administrativa a nivel local. Se trata de cuatro 
instancias gubernamentales: el Consejo de Desarrollo de las Nacionalidades y Pueblos del Ecuador (CODENPE) creado en 1998 con rango de Ministerio y adscrito a la Presidencia de la República, la Dirección Nacional de Educación Intercultural Bilingüe (DINEIB) creada en 1988, la Dirección Nacional de Salud Indígena reconocida en 1999 y el Fondo de Desarrollo de los Pueblos Indígenas (FODEPI) creado en el 2002. En todos estos espacios los directivos son nombrados de una terna presentada por el movimiento. Además deben cumplir el mandato asignado y rendir cuentas periódicas de su gestión. Aunque no lograron representación corporativa en el Congreso Nacional, se aprobó la creación, en el año 2000, de la Comisión de Asuntos Indígenas y otras Etnias al interior del Congreso y, en 1997, se abrió un espacio de defensa de sus derechos al interior del Estado, la Defensoría de los Pueblos Indígenas (DINAPIN) como parte de la Defensoría del Pueblo ${ }^{6}$.

En cuanto a los espacios de autonomía política y administrativa, las reformas constitucionales de 1998 y 2008 crearon las circunscripciones territoriales indígenas (CTI) ${ }^{7}$, concebidas como espacios geográficos que se sustentan en la propiedad colectiva e inalienable de la tierra, la práctica de sus propias costumbres, modelos organizativos y sistema de derecho propio, así como en la elección de sus autoridades para autogobernarse. Sin embargo, la agitación política que ha vivido el país luego de las reformas constitucionales y la falta de acuerdo dentro del movimiento indígena no han hecho posible su creación hasta la fecha.

Una última condición para la creación de un mecanismo electoral por parte del movimiento indígena tiene que ver con la crisis que el resto de movimientos sociales sufrió a partir de 1990. El movimiento sindical entró en un proceso de atomización luego de las reformas del Código de Trabajo (2005) y de la privatización de algunas empresas del Estado ${ }^{8}$; el

6 Las defensorías del pueblo se institucionalizaron en Colombia en 1992, en Perú en 1996, en Bolivia en 1998 y en Venezuela en 1999.

7 En Colombia corresponden a los resguardos indígenas, en Bolivia a las tierras comunitarias de origen (TCO) y en Venezuela y Perú a los municipios indígenas.

8 Permanecen entre los más importantes los sindicatos de maestros, trabajadores de la salud, trabajadores petroleros y los servidores públicos. 
movimiento de las mujeres ha logrado interesantes avances en materia de derechos, igualmente el ambientalista y de derechos humanos, pero no han contado con el grado de movilización nacional que los indígenas han mostrado. En este sentido, al interior de la sociedad ecuatoriana, la propuesta de los pueblos indígenas se da en un contexto de ausencia de iniciativas del resto de la sociedad civil que permitan formular y negociar pedidos, generar críticas e imaginar nuevas alternativas.

Los antecedentes mencionados sirven para explicar tanto los factores de la permanencia de Pachakutik durante diecisiete años, así como sus triunfos y derrotas. Un primer factor tiene que ver con la presencia de una densa red de organizaciones de base ubicadas especialmente en las zonas rurales de las provincias serranas y amazónicas del país. Esta conformación es resultado de un proceso histórico que tiene sus inicios en la década de 1960 y que ha permanecido en el tiempo como resultado de la lucha que el movimiento ha mantenido contra el Estado utilizando acciones ilegales para luego lograr su legalidad.

En el caso ecuatoriano existen circunscripciones electorales donde la densidad indígena de votantes es mayoritaria o es una minoría significativa; según Van Cott (2005) el 42,9\% del total de las circunscripciones electorales tiene esta característica, de las veinticuatro provincias que conforman el país, tres tienen mayoría indígena y seis una minoría significativa. Este hecho fue aprovechado por el movimiento, en el IV Congreso de la CONAIE, para lanzar una nueva estrategia política de largo plazo: tomarse los poderes locales por la vía democrática y electoral en las zonas donde los indígenas eran mayoría o minoría significativa, para acceder posteriormente a la toma del poder nacional.

Estas acciones, a su vez, van a formar parte de una estrategia más estructural del movimiento que combina la utilización de modos alternativos de participación política identificados como formas de desobediencia civil, como los levantamientos, con otras de obediencia civil, como los procesos electorales. Paralelamente existe otro factor institucional que favoreció esta decisión del movimiento indígena, se trata del inicio del proceso de descentralización iniciado en el país en 1983, lo cual per- 
mitió que los municipios se fortalezcan y se conviertan en escenarios de enfrentamiento político menos exigentes que las elecciones nacionales para aquellos movimientos como Pachakutik que se estrenaban en las lides electorales y que además contaban con organizaciones consolidadas y fuertes. No hay que olvidar también que el proceso de descentralización proporciona un marco estructural idóneo para el ejercicio de uno de los pilares principales sobre los que se asienta el movimiento indígena: la construcción de las autonomías regionales y locales.

Además, es importante mencionar que el Movimiento de Unidad Plurinacional Pachakutik, desde su inicio, se va a ubicar dentro de la izquierda política del país, lo cual le dará mayor protagonismo ya que los partidos de la izquierda tradicional habían disminuido su votación a favor de los partidos de derecha, centro y populistas luego del retorno a la democracia en 1979. Un amplio sector de profesionales e intelectuales no indígenas de la clase media, decepcionados de las opciones izquierdistas, van a sumarse al movimiento Pachakutik que desde su conformación va a tener un carácter multiétnico. En el proceso de su constitución se discutió el tema de la plurinacionalidad y de la interculturalidad. El movimiento decidió que no debía ser solo de indígenas o para indígenas sino que tenía que emprender procesos de inclusión de otros sectores sociales, culturales y étnicos.

Tabla 1.

Participación de Pachakutik en las elecciones presidenciales desde 1996 a 2013

\begin{tabular}{c|c|c}
\hline Año de elección & $\begin{array}{c}\text { Porcentaje de } \\
\text { votación }\end{array}$ & Lugar \\
\hline 1996: $1 .^{\circ}$ vuelta & 17,35 & Tercero \\
\hline 1998: $1 .^{\circ}$ vuelta & 14,74 & Cuarto \\
\hline 2002: $1 .^{\circ}$ vuelta & 20,64 & Primero \\
2002: $2 .^{\circ}$ vuelta & 54,79 & Primero \\
\hline 2006: $1 .^{\circ}$ vuelta & 2,19 & Sexto \\
\hline 2009: $1 .^{\circ}$ vuelta & - & Sin candidato \\
\hline $2013: 1 .^{\circ}$ vuelta & 3,26 & Sexto \\
\hline
\end{tabular}

Fuente: Consejo Nacional Electoral (2013). Elaboración propia 
La revisión del desempeño logrado por Pachakutik en los trece procesos electorales que ha intervenido es muy ilustrativa. La Tabla 1 muestra las siete elecciones presidenciales en las que ha participado, cinco en alianza con otros movimientos y partidos, en la quinta con candidato indígena y en la penúltima no tuvo candidato. Se lograron los siguientes resultados: en 1996 obtuvo el tercer lugar; en 1998 bajó al cuarto lugar con el 14,74\%; en el 2002 alcanzó el primer lugar con el 20,64\% de los sufragios en la primera vuelta y el $54,79 \%$ en la segunda vuelta; en el 2006 el sexto puesto con el 2,19\%; en el 2009 no tuvo candidato, y en el 2013 el sexto puesto con el 3,26\%.

Tabla 2.

Participación de Pachakutik en las elecciones legislativas y para Asambleas

\begin{tabular}{c|c|c|c}
\hline $\begin{array}{c}\text { Elección legis- } \\
\text { lativa/ Asam- } \\
\text { blea }\end{array}$ & $\begin{array}{c}\text { Cantidad de legis- } \\
\text { ladores/asambleís- } \\
\text { tas obtenidos }\end{array}$ & $\begin{array}{c}\text { Total legisladores/ } \\
\text { asambleístas electos }\end{array}$ & $\begin{array}{c}\text { Porcentaje de repre- } \\
\text { sentación }\end{array}$ \\
\hline 1996 & 8 & 82 & 9,75 \\
\hline 1997 Asamblea & 10 & 70 & 14,28 \\
\hline 1998 & 6 & 121 & 4,95 \\
\hline 2002 & 10 & 100 & 10 \\
\hline 2006 & 6 & 100 & 6,07 \\
\hline 2007 Asamblea & 4 & 130 & 3,22 \\
\hline 2009 & 5 & 124 & 3,64 \\
\hline 2013 & 4 & 137 & \\
\hline
\end{tabular}

Fuente: Consejo Nacional Electoral (2013). Elaboración propia

La Tabla 2 presenta los resultados de las elecciones para las dos Asambleas Constituyentes, la de 1997 en la que fueron nominados diez asambleístas por Pachakutik de un total de setenta (el 14,28\%) y la de 2007, donde solamente cinco asambleístas por Pachakutik fueron

9 Hay que puntualizar que ninguno de los candidatos participantes fue indígena. 
electos de un total de ciento treinta (el 3,07\%). En las elecciones legislativas de 1996 Pachakutik logró ocho diputados (uno nacional y siete provinciales) de un total de ochenta y dos (9,75\%), en las de 1998 bajó su participación al obtener seis diputados (dos nacionales y cuatro provinciales) de un total de ciento veintiún diputados (4,95\%), en las de 2002 aumentó a once diputados provinciales de un total de cien (11\%), en el 2006 obtuvo seis diputados provinciales de un total de cien (6\%), en el 2009 cuatro asambleístas provinciales de un total de ciento veinticuatro $(3,22 \%)$ y finalmente en el 2013 cinco asambleístas, uno nacional y cuatro provinciales de un total de ciento treinta y siete $(3,64 \%)$.

Tabla 3.

Participación de Pachakutik en las elecciones de prefectos provinciales

\begin{tabular}{c|c|c|c}
\hline Años de elección & N. $^{\text {o }}$ prefectos & Total prefectos & Porcentaje \\
\hline 1996 & 0 & 22 & 0 \\
\hline 2000 & 5 & 22 & 22,72 \\
\hline 2004 & 4 & 22 & 18,18 \\
\hline 2009 & 5 & 23 & 21,73 \\
\hline
\end{tabular}

Fuente: Consejo Nacional Electoral (2013). Elaboración propia

Tabla 4.

Participación de Pachakutik en las elecciones de consejeros provinciales

\begin{tabular}{c|c|c|c}
\hline Años de elección & N. $^{*}$ consejeros & Total consejeros & Porcentaje \\
\hline 1996 & 0 & 89 & 0 \\
\hline 2000 & 11 & 89 & 12 \\
\hline 2004 & 14 & 91 & 15,38 \\
\hline
\end{tabular}

Nota: La Constitución (2008) suprimió las nominaciones de consejeros provinciales

Fuente: Consejo Nacional Electoral (2013). Elaboración propia 
Tabla 5.

Participación de Pachakutik en las elecciones de alcaldes

\begin{tabular}{c|c|c|c}
\hline Ańos de elección & N. $^{\circ}$ alcaldes & Total alcaldes & Porcentaje \\
\hline 1996 & 0 & 214 & 0 \\
\hline 2000 & 31 & 215 & 14,40 \\
\hline 2004 & 27 & 219 & 12,32 \\
\hline 2009 & 21 & 221 & 9,50 \\
\hline
\end{tabular}

Fuente: Consejo Nacional Electoral (2013). Elaboración propia

Tabla 6.

Participación de Pachakutik en las elecciones de concejales municipales

\begin{tabular}{c|c|c|c}
\hline Ańos de elección & N. $^{\circ}$ concejales & Total concejales & Porcentaje \\
\hline 1996 & 0 & 860 & 0 \\
\hline 2000 & 84 & 880 & 9,50 \\
\hline 2004 & 118 & 893 & 13,20 \\
\hline 2009 & 120 & 1581 & 7,59 \\
\hline
\end{tabular}

Fuente: Consejo Nacional Electoral (2013). Elaboración propia

Las Tablas de la 3 a la 6 exhiben los resultados en cuanto a los gobiernos locales en los comicios de 1996 donde fueron elegidos alrededor de cincuenta funcionarios públicos en las diversas nominaciones, pero ningún alcalde o prefecto. En el año 2000 obtuvieron cinco de las veintidós prefecturas provinciales, equivalente al 22,72\% del total; treinta y uno de las doscientas quince alcaldías, equivalentes al 14,40\% del total; once de los ochenta y nueve consejeros elegidos, equivalentes al $12 \%$ del total; ochenta y cuatro de los ochocientos ochenta concejales elegidos, equivalentes al 9,5\% del total. El movimiento Pachakutik logró alrededor del 5,1\% de la votación nacional constituyéndose en la quinta fuerza electoral del país a esa fecha.

Para considerar los resultados de las elecciones de 2004 es importante tener en cuenta el desgaste político que sufrió el movimiento Pachakutik debido a la alianza que hizo con el Gobierno del Coronel 
Lucio Gutiérrez durante los siete primeros meses del 2003. Los resultados fueron los siguientes: ganaron cuatro de las veintidós prefecturas provinciales, equivalentes al 18,18\% del total; veintisiete de las doscientas diecinueve alcaldías, equivalentes al 12,32\% del total; catorce de los noventa y un consejeros elegidos, equivalentes al 15,38\% del total; ciento dieciocho de los ochocientos noventa y tres concejales elegidos, equivalentes al 13,2\% del total. El movimiento Pachakutik logró alrededor del 7,7\% de la votación nacional, manteniéndose como la quinta fuerza electoral del país.

Finalmente, en las elecciones de 2009, época del Movimiento Alianza PAIS y el Presidente Correa, los resultados a nivel local no muestran cambios sustanciales. Lograron cinco de las veintitrés prefecturas, equivalente al 21,23\% del total; de las doscientas veintiún alcaldías alcanzaron veintiuna, equivalente al 9,50\% del total; los consejeros provinciales desaparecieron luego de la Constitución de 2008 y de un total de mil quinientos ochenta y uno concejales municipales, tanto urbanos como rurales, fueron elegidos ciento veinte, equivalentes al 7,59\% del total. El movimiento $\mathrm{Pa}$ chakutik mantuvo el quinto lugar en las preferencias electorales nacionales.

Tabla 7.

Votación de las consultas populares de 2007 y 2008 en nueve provincias de población indígena mayoritaria y minorías significativas

\begin{tabular}{c|c|c|c|c}
\hline Provincias & $\begin{array}{c}\text { Consulta } \\
\text { 2007/SÍ }\end{array}$ & $\begin{array}{c}\text { Consulta } \\
\text { 2007/NO }\end{array}$ & $\begin{array}{c}\text { Consulta } \\
\text { 2008/Sí }\end{array}$ & $\begin{array}{c}\text { Consulta } \\
\text { 2008/NO }\end{array}$ \\
\hline Nacional & 81,72 & 12,43 & 63,93 & 28,10 \\
\hline Napo & 56,09 & 37,59 & 38,79 & 55,43 \\
\hline Morona Santiago & 82,91 & 11,12 & 65,64 & 25,73 \\
\hline Chimborazo & 80,98 & 9,67 & 62,17 & 27,06 \\
\hline Pastaza & 82,90 & 11,55 & 56,40 & 35,68 \\
\hline Orellana & 76,84 & 16,41 & 46,73 & 45,85 \\
\hline Imbabura & 86,99 & 7,08 & 75,41 & 17,02 \\
\hline Cotopaxi & 84,65 & 7,23 & 68,51 & 22,29 \\
\hline Bolívar & 80,74 & 10,23 & 53,21 & 35,91 \\
\hline Cañar & 82,61 & 10,69 & 69,52 & 21,52 \\
\hline
\end{tabular}

Fuente: Consejo Nacional Electoral (2013). Elaboración propia 
La Tabla 7 ofrece una panorámica de la votación del sí y del no en nueve provincias. En la consulta popular de 2007, donde se preguntó sobre la convocatoria e instalación de la Asamblea Constituyente, en nueve provincias ganó el sí y solamente en cuatro de las nueve la votación del sí fue inferior al porcentaje nacional. En la consulta popular de 2008, en cambio, se preguntó sobre la aprobación o no de la nueva Constitución de la República del Ecuador, solamente en una provincia ganó el no, en las ocho restantes el sí aunque solamente en cinco de las nueve la votación del sí fue inferior al porcentaje nacional.

Tabla 8.

Votación de la consulta popular de 2011 en nueve provincias de población indígena mayoritaria y minorías significativas

\begin{tabular}{c|c|c|c|c|c|c|c|c|c|c}
\hline Provincias & $\begin{array}{c}\text { Preg.1 } \\
\text { Sí }\end{array}$ & $\begin{array}{c}\text { Preg. 2 } \\
\text { NO }\end{array}$ & $\begin{array}{c}\text { Preg. 2 } \\
\text { Sí }\end{array}$ & $\begin{array}{c}\text { Preg. 2 } \\
\text { NO }\end{array}$ & $\begin{array}{c}\text { Preg. 3 } \\
\text { SÍ }\end{array}$ & $\begin{array}{c}\text { Preg. 3 } \\
\text { NO }\end{array}$ & $\begin{array}{c}\text { Preg. 4 } \\
\text { Sí }\end{array}$ & $\begin{array}{c}\text { Preg. 4 } \\
\text { NO }\end{array}$ & $\begin{array}{c}\text { Preg. 5 } \\
\text { Sí }\end{array}$ & $\begin{array}{c}\text { Preg. 5 } \\
\text { NO }\end{array}$ \\
\hline Nacional & 50,46 & 38,87 & 48,27 & 40,83 & 47,18 & 41,88 & 46,15 & 42,55 & 46,66 & 41,95 \\
\hline Napo & 37,18 & 54,74 & 34,91 & 56,35 & 34,35 & 57,36 & 33,39 & 57,57 & 33,57 & 57,31 \\
\hline Morona Santiago & 30,53 & 60,97 & 29,16 & 61,51 & 28,33 & 62,64 & 27,34 & 63,20 & 27,64 & 62,75 \\
\hline Chimborazo & 39,12 & 46,23 & 37,24 & 47,89 & 36,47 & 48,85 & 35,36 & 49,48 & 38,52 & 48,68 \\
\hline Pastaza & 37,15 & 58,87 & 39,91 & 55,61 & 34,20 & 56,54 & 33,11 & 57,19 & 33,50 & 56,59 \\
\hline Orellana & 40,68 & 48,18 & 38,70 & 50,51 & 38,23 & 51,15 & 37,74 & 51,05 & 37,98 & 50,60 \\
\hline Imbabura & 50,49 & 38,43 & 48,38 & 40,19 & 47,63 & 41,00 & 46,01 & 42,15 & 46,72 & 41,41 \\
\hline Cotopaxi & 36,68 & 49,99 & 34,66 & 51,74 & 34,31 & 52,10 & 33,10 & 53,00 & 33,64 & 52,44 \\
\hline Bolívar & 31,74 & 52,58 & 30,22 & 53,95 & 29,62 & 54,75 & 28,81 & 54,91 & 29,19 & 54,29 \\
\hline Cańar & 45,68 & 42,39 & 43,52 & 44,23 & 42,92 & 44,86 & 41,92 & 45,46 & 42,58 & 44,72 \\
\hline
\end{tabular}

Fuente: Consejo Nacional Electoral (2013). Elaboración propia 
Tabla 9.

Votación de la consulta popular de 2011 en nueve provincias de población indígena mayoritaria y minorías significativas

\begin{tabular}{c|c|c|c|c|c|c|c|c}
\hline Provincias & $\begin{array}{c}\text { Preg. 6 } \\
\text { SÍ }\end{array}$ & $\begin{array}{c}\text { Preg. 6 } \\
\text { NO }\end{array}$ & $\begin{array}{c}\text { Preg. 7 } \\
\text { Sí }\end{array}$ & $\begin{array}{c}\text { Preg. 7 } \\
\text { NO }\end{array}$ & $\begin{array}{c}\text { Preg. 9 } \\
\text { SÍ }\end{array}$ & $\begin{array}{c}\text { Preg. 9 } \\
\text { NO }\end{array}$ & $\begin{array}{c}\text { Preg. 10 } \\
\text { Sí }\end{array}$ & $\begin{array}{c}\text { Preg. 10 } \\
\text { NO }\end{array}$ \\
\hline Nacional & 46,59 & 40,61 & 45,76 & 41,68 & 44,96 & 42,04 & 48,02 & 39,24 \\
\hline Napo & 34,18 & 55,12 & 34,78 & 54,27 & 32,56 & 56,36 & 35,89 & 53,24 \\
\hline Morona Santiago & 27,81 & 61,53 & 28,47 & 60,54 & 27,08 & 61,88 & 28,18 & 60,53 \\
\hline Chimborazo & 35,23 & 47,14 & 35,25 & 47,21 & 33,61 & 48,54 & 35,61 & 46,64 \\
\hline Pastaza & 34,02 & 54,96 & 34,76 & 54,01 & 32,58 & 55,98 & 34,26 & 54,42 \\
\hline Orellana & 37,74 & 49,13 & 39,06 & 47,93 & 36,53 & 49,92 & 39,29 & 47,38 \\
\hline Imbabura & 47,38 & 39,73 & 47,32 & 39,98 & 45,32 & 41,51 & 48,27 & 38,90 \\
\hline Cotopaxi & 34,10 & 50,40 & 34,88 & 49,44 & 32,41 & 51,79 & 34,98 & 49,34 \\
\hline Bolívar & 28,70 & 52,77 & 29,61 & 51,83 & 27,41 & 53,76 & 28,73 & 52,53 \\
\hline Cańar & 42,38 & 43,52 & 43,09 & 42,09 & 40,86 & 44,74 & 41,94 & 43,80 \\
\hline
\end{tabular}

Fuente: Consejo Nacional Electoral (2013). Elaboración propia

Las Tablas 8 y 9 muestran los resultados de la consulta popular de 2011, en la cual se hicieron diez preguntas (nueve a nivel nacional y una a nivel cantonal), los resultados en las nueve provincias, a diferencia de las consultas de 2007 y 2008, fue mayoritariamente a favor del no. A pesar de que en los resultados nacionales triunfó el sí, la respuesta indígena a las nueve preguntas fue por el no.

De la revisión de los resultados anteriores se concluye algunas características de la participación electoral de Pachakutik. Resulta difícil trazar un límite hasta donde es movimiento social y hasta donde es movimiento político o partido. A pesar de que sus dirigentes no admiten la denominación de partido para señalar su malestar con el sistema de partidos vigente en el país, la organización cumple determinadas funciones que son atribuibles a los partidos políticos ${ }^{10}$. Lo que sí es cierto es que

10 Partido entendido en el sentido que menciona Cotarelo: “...toda asociación voluntaria perdurable en el tiempo. Dotada de un programa de gobierno de la sociedad en su conjunto, que canaliza de- 
la estructura organizativa del movimiento social ha servido para el funcionamiento del movimiento político, sobre todo en lo concerniente a la relación cercana entre bases y líderes, en la presencia de mecanismos colectivos en la toma de decisiones y en la vigencia de una estructura poco burocratizada.

A pesar de que el movimiento representa intereses y demandas que no son solo indígenas, no ha logrado integrar una propuesta interclasista y de alcance nacional, como lo demuestran sus triunfos en circunscripciones electorales de concentración indígena y su ausencia total en otras áreas electorales importantes, como son las cinco provincias de la Costa ecuatoriana. El movimiento, en el caso ecuatoriano, a diferencia de otros movimientos indígenas de la región, ha logrado participar en diversas instancias (locales, regionales y nacionales) de ejercicio del poder. Sin embargo, la acción más perdurable y exitosa descansa en la ejercida en los gobiernos locales ${ }^{11}$. Por último, el movimiento también tiene el mérito de haber incorporado en la agenda política ecuatoriana algunos temas que el país requiere discutirlos para poder generar políticas de Estado, como por ejemplo la diversidad cultural y étnica, la plurinacionalidad, las autonomías, la interculturalidad, el pluralismo legal y las nuevas formas de participación y representación política.

\section{La relación entre movimiento social y movimiento electoral}

Luego de la participación en el golpe de Estado del año 2000 y de su alianza efímera con el Gobierno del ex Presidente Gutiérrez, en el 2003, a la fecha el movimiento indígena ecuatoriano vive una curiosa paradoja. Luego de haber alcanzado el protagonismo político más importante de los últimos años en el país entra en un punto de quiebre y declive que lo mantiene desarticulado, ante lo cual cabe preguntarse si se trata de un repliegue

terminados intereses sectoriales y que aspira a ejercer el poder político o a participar en él mediante su presentación reiterada en los procesos electorales" (1995:14).

11 Ver García y Tibán (2008) como ejemplo de análisis de un gobierno local dirigido por autoridades indígenas. 
estratégico, o del agotamiento del movimiento indígena como sujeto histórico, o resultado de la constitución del movimiento Pachakutik.

La pugna entre el movimiento político y el movimiento social (denominado en este trabajo como el efecto Pachakutik), se ha centrado en situaciones coyunturales de lucha y decisiones, en las cuales uno de ellos ha dejado al otro fuera de juego. El primero definido y condicionado desde el sistema de partidos controlado por la estructura oligárquica del poder y el segundo obligado al cumplimiento de su proyecto político e histórico. Estas divergencias, por ejemplo, se volvieron dramáticas al momento de decidir la alianza electoral que le dio el triunfo al Coronel Gutiérrez en el 2002. Mientras el primero fue seducido por el acceso al poder, el segundo pugnaba por mantener su estrategia de movilización y resistencia, pero sin contar con la aprobación de sus bases para legitimar la alianza.

La polémica se agudiza desde que el movimiento social decide crear Pachakutik como mecanismo electoral con el fin de luchar desde el interior del Estado neoliberal para lograr su propio espacio de poder. Esta estrategia, una vez transcurridos quince ańos de vigencia, muestra diversos balances entre los mismos actores del movimiento. Me permito utilizar el testimonio de dos líderes indígenas nacionales para ilustrar el mencionado efecto Pachakutik:

Nosotros nos preparamos para ser un movimiento contestario que lucha por el reconocimiento de sus derechos, pero no nos preparamos para gobernar. Nosotros hemos tenido en dos ocasiones el poder en nuestras manos [por golpe de Estado y mediante las elecciones] pero no hemos durado más de seis meses en esos espacios. Yo diría que uno de los grandes errores que hemos cometido es el habernos preocupado única y exclusivamente del tema ideológico político, de las acciones relacionadas al acceso del poder local o nacional, más no en la construcción de un poder que sea una alternativa al orden establecido (entrevista a Luis Maldonado, 2005).

Parecería que la participación de los cuadros indígenas en cargos de representación pública se convirtió en la prioridad coyuntural del movimiento social, descuidando dos estrategias claves: la propuesta política 
de la construcción del Estado plurinacional e intercultural y la relación con las organizaciones de base. La opinión del otro líder indígena es más determinante:

Una de las últimas resoluciones de la CONAIE es que el movimiento indígena no participe en ninguna de las instituciones públicas, porque yo creo que una de las causas de que el movimiento indígena haya sufrido un desgaste fue la participación en las elecciones presidenciales del 2002. De tal modo que nosotros decimos que es necesario volver a lo nuestro, para que desde ahí podamos tomar fuerzas y retomar el vigor para no dispersarnos en las funciones públicas. Hemos tenido más éxito cuando estuvimos fuera de la institucionalidad, cuando estuvimos dentro logramos muy poco (entrevista a Luis Macas, 2005).

Este testimonio muestra el fracaso de participar políticamente a través de los mecanismos institucionales (principalmente en el poder Ejecutivo y Legislativo y los gobiernos locales) y la necesidad de "volver a lo nuestro", que implica la recuperación de la relación con las bases del movimiento y la diferenciación de saber medir la efectividad de la fuerza política y de la fuerza social.

Sin embargo, la solución final para el futuro del movimiento no parece estar en ninguno de los dos extremos, resistir como movimiento social utilizando mecanismos de protesta y movilización no institucionales o incidir como movimiento político en el marco de la institucionalidad estatal. El mismo dirigente indígena nos ofrece una respuesta:

Yo creo que hay que combinar el camino de las protestas y movilizaciones con el de la participación en las instancias de poder nacional y local. No hay que abandonar lo uno y priorizar lo otro. Las dos estrategias son absolutamente necesarias para que el movimiento indígena pueda conseguir su mayor reivindicación: la construcción de un Estado plurinacional e intercultural (entrevista a Luis Macas, 2005).

A continuación quisiera seńalar algunos efectos positivos y negativos que la participación del movimientos indígena ecuatoriano ha tenido 
sobre el proceso de democratización del país. El primero muestra, contrariamente a la literatura sobre partidos políticos, que la presencia de organizaciones políticas étnicas no ha exacerbado el conflicto interétnico al interior de la nación, más bien el movimiento indígena ha privilegiado un discurso nacionalista, en parte, porque su viabilidad electoral depende en gran medida de atraer a los votantes no indígenas y, por otra parte, porque se han dado cuenta que una posición separatista en la actualidad no tiene futuro.

El segundo se relaciona con que el discurso de las organizaciones indígenas en las dos últimas décadas ha sido de inclusión y de participación equitativa con los otros sectores sociales y culturales, se trataría de canalizar los conflictos étnicos a través del sistema político formal sobre la base del diálogo y el respeto para incentivar la realización de alianzas mutiétnicas.

El tercer efecto es que la incorporación de sectores sociales tradicionalmente excluidos de las instituciones democráticas, en especial en países con población indígena mayoritaria, permite que esas instituciones recuperen legitimidad y representatividad. El cuarto demuestra que los movimientos políticos indígenas mantienen fuertes vínculos con la sociedad civil a través de los movimientos sociales y organizaciones afiliadas de los cuales surgieron. Una nueva forma de representación estaría consolidándose basada en el ejercicio de un mandato colectivo que demanda rendición de cuentas periódica y posibilidad de revocatoria en caso de incumplimiento.

Otro efecto importante es que la agenda de los movimientos políticos indígenas ha introducido nuevos temas en el discurso político nacional que obliga no solamente a su debate sino que fuerza al resto de partidos a incorporarlos en sus agendas, tales como el reconocimiento y respeto a la diversidad cultural, el debate sobre las diferentes formas de discriminación (racial, de género, orientación sexual, generación, discapacidad) y las autonomías regionales y locales. El último efecto positivo está vinculado con la introducción de una nueva forma de hacer política, basada en la lucha contra la corrupción y los pactos políticos 
fantasmas, junto con el compromiso de denuncia pública y sanción cuando esto suceda. Además de la defensa sistemática de la soberanía en sus diversas aplicaciones (territorial, alimentaria, recursos naturales, conocimientos, etc.). Esta nueva forma de hacer política también se manifiesta al interior de los movimientos políticos indígenas que tratan de mantener una estructura más democrática y participativa. Igualmente, hay muchos ejemplos de gobiernos locales dirigidos por indígenas que han introducido nuevas formas de representación y participación en su gestión.

Los efectos negativos también requieren ser analizados. El primero tiene que ver con el fraccionamiento de las organizaciones indígenas nacionales provocadas desde el Gobierno y por pugnas electorales. En Ecuador, un ejemplo dramático se vivió en el Gobierno del Coronel Gutiérrez, luego de la ruptura de la alianza con Pachakutik, en el cual dos organizaciones indígenas nacionales diferentes a la CONAIE entraron en franca colaboración con el Gobierno, así como también muchas organizaciones regionales y locales afiliadas a la misma CONAIE que cayeron en la tentación de apoyo al entonces Presidente como pago a la asistencia económica gubernamental que recibieron.

El segundo efecto negativo muestra la existencia de funcionarios indígenas que una vez en ejercicio de su cargo dejan a un lado los intereses colectivos que representan y ponen en primer lugar sus intereses individuales, rompiendo de esta manera una práctica cultural propia que ha sido reivindicada por el movimiento. Existen muchos casos de autoridades indígenas elegidas por votación popular que han traicionado al movimiento y han sido desconocidas y expulsadas.

El tercero, reduce la efectividad del movimiento cuando sus representantes se concentran en disputas internas de poder por acceder a la nominación, distraen su acción en temas que no son prioritarios o negocian directamente con funcionarios del Gobierno desplazando a los líderes del movimiento. Todos estos factores pueden atentar contra la identidad, la organización y la unidad de las organizaciones indígenas. 
El cuarto evidencia que los funcionarios indígenas elegidos, en muchos casos, carecen de experiencia política y capacidad técnica para un buen desempeño en su cargo. Este hecho plantea, por un lado, una desventaja ya que les lleva a depender de asesores no indígenas que tienden a interferir en sus decisiones. Por otro lado, presenta un reto ya que a pesar de ser resultado de la falta de oportunidades que los indígenas han tenido respecto a los no indígenas, al no poder acceder a la educación formal, les enfrenta a avanzar en su calificación educativa y en el conocimiento de las normas y procedimientos burocráticos.

El último efecto tiene que ver con que los funcionarios indígenas deben responder al hecho de que son representantes no solamente de las demandas de los pueblos indígenas, sino que deben responder también a las de otros sectores no indígenas que también los eligieron. Esta situación, característica de distritos interculturales, demanda de estos funcionarios un continuo balance en el cumplimiento de su mandato.

\section{Reflexiones hacia el futuro}

El análisis del desempeño electoral de Pachakutik en más de una década plantea algunas reflexiones sobre su futuro en la escena política nacional. La revisión de resultados electorales muestra una doble trayectoria que debe ser explicada. La primera respecto a la votación más de carácter nacional de presidente, vicepresidente y legisladores. En las siete elecciones presidenciales realizadas en el periodo analizado se encuentra un claro desequilibrio: de cerca del 20\% obtenido, se pasó a más del $50 \%$, para terminar en el 0\%. Respecto a diputados y asambleístas el porcentaje bajó del 14\% al 3\% en ocho procesos electorales. En este campo hay una evidente debacle del desempeño de Pachakutik como movimiento político.

La segunda trayectoria tiene que ver con la elección de autoridades de los gobiernos locales y en este sentido su desempeño es diferente. En realidad el proceso electoral de 1996 casi no cuenta por ser el primero, 
si se analiza el del 2000, 2004 y 2009 se encuentra que respecto a prefectos provinciales se mantiene entre $18 \%$ y $22 \%$, en alcaldes hay una pequeña baja del $5 \%$, mientras en lo referido a consejeros provinciales y concejales municipales la votación fluctúa entre 7\% y $14 \%$. Lo cual permite verificar que la debacle obtenida en las elecciones de dignidades nacionales no se repite cuando se trata de dignidades seccionales.

La explicación de estos hechos ha sido formulada por varios autores, me refiero a los trabajos conjuntos de Mijeski y Beck (2000; 2001; 2004; 2006; 2008) y de Báez y Bretón (2006). Los principales argumentos esgrimidos por ellos son la fragmentación entre movimiento social y movimiento político a partir de la participación en el golpe antidemocrático del ańo 2000. Desde esa fecha se inicia un alejamiento cada vez mayor entre la dirigencia histórica del movimiento y las bases organizadas. Fractura que se va a volver a repetir por dos ocasiones más: en la alianza con el ex-Presidente Gutiérrez y en la negación de la alianza con Rafael Correa en las elecciones de 2006, donde la dirigencia prefirió ir con un candidato indígena propio, con los resultados ya conocidos. Esta fractura interna aún no ha sido subsanada y acompańa al movimiento especialmente en la región amazónica donde se mantuvo hace poco la presencia de dos directivas de la Confederación de Nacionalidades Indígenas de la Amazonia Ecuatoriana (CONFENIAE), una organización fiel a la CONAIE y otra disidente.

Otro punto crítico es la ausencia o fracaso de alianzas con otros sectores sociales y políticos. Los episodios más relevantes de esta situación se vivieron en 1998 con la creación de la Asamblea Popular, en el 2000 y la formación de la Coordinadora de Movimientos Sociales, y en el 2003 con la alianza de Pachakutik y el ex-Presidente Gutiérrez. La falta de apoyo de sectores no indígenas a los planteamientos de Pachakutik lo muestra como esencialmente indígena. Por tanto, se hace indispensable pensar el Estado plurinacional e intercultural desde un doble marco: el identitario nacional y no solamente el indígena, y el de la relación con el proyecto político de la interculturalidad. Para lograr la verdadera plurinacionalidad se deben juntar todas las fuerzas sociales en su diferencia y diversidad. 
El movimiento consumió la mayor cantidad de su energía en los ajetreos electorales que se convirtieron en el principal anzuelo de gran parte de la dirigencia. Este ejercicio les llevó a una especie de activismo político que les inhabilitó para mantener en la agenda de discusión los grandes temas propuestos por el movimiento en su programa político del IV Congreso. Me refiero a planteamientos como el del Estado plurinacional e intercultural, la legalización y delimitación de territorios, la puesta en marcha de las circunscripciones territoriales indígenas aprobadas en la Constitución de 1998 y de 2008 y la discusión de las autonomías indígenas, entre los más importantes. No hay que olvidar que estos factores fueron históricamente los que movilizaron a las bases indígenas y no indígenas y que su continua postergación desencantó a sus seguidores. Una conclusión provisional sería que Pachakutik ha fracasado en atraer a la mayoría indígena del país, no solo de las otras dos organizaciones indígenas nacionales FEINE y FENOCIN, sino también de la misma CONAIE.

La pérdida de votación en los resultados mostrados enseña que dentro de la cultura política ecuatoriana la vigencia del clientelaje político es todavía una cruda realidad. Me refiero a la baja votación lograda en las provincias costeńas, en especial en la ciudad de Guayaquil, debido a la presencia de dos partidos políticos clientelares, el uno de la derecha (Partido Social Cristiano) y el otro populista (Partido Roldosista Ecuatoriano). Lo mismo se puede decir respecto a las otras dos regiones, Sierra y Amazonía donde, desde el año 2002, se disputan la votación con otro partido populista, el Partido Sociedad Patriótica, del ex-Presidente Gutiérrez. Como se puede observar, la mayoría del electorado ecuatoriano no es portador de un voto fundamentalmente ideológico sino más bien coyuntural y emotivo.

Una de las evidencias que muestran las publicaciones de la Fundación Q'uellkaj (2005; 2006) en la observación del electorado intercultural realizado en los procesos de 2004 y 2006, es justamente el hecho de la alta presencia de votos nulos ${ }^{12}$. La explicación tiene varias

12 En la primera vuelta de las elecciones presidenciales de 2006 el porcentaje de votación indígena fue primero Gilmar Gutiérrez, segundo votos nulos, tercero Correa y cuarto Macas. 
respuestas: las dificultades que tiene el electorado analfabeto para emitir el voto escrito; la discriminación por parte de los miembros de las juntas receptoras del voto, que en su gran mayoría son mestizos, a los votantes indígenas, en especial a las mujeres y el desconocimiento de las propuestas de cada movimiento o partido por parte de los electores. Este voto nulo, en realidad, ha representado en el periodo 1978-2002 una media de 8,35 en las elecciones de dignidades nacionales, cifra que en algunos casos supera inclusive el porcentaje nacional obtenido por Pachakutik.

Otra pregunta importante que plantea el desempeño de Pachakutik es si se trata de un movimiento político más o es un ejemplo de una nueva forma de hacer politica en el país. O planteado de otra manera, ¿qué es lo que le diferencia del resto de partidos o movimientos? Respecto a su comportamiento Legislativo y en la época de la alianza con Gutiérrez en el Ejecutivo no se encuentran diferencias notables. Se recurrió al manejo 'politiquero' de las cuotas políticas en representaciones públicas que nombra el Congreso Nacional y a diversas formas de clientelaje político en la ejecución de los programas sociales del Estado. Lo rescatable tal vez esté en algunas prácticas de participación y representación lograda en algunos gobiernos locales dirigidos por autoridades indígenas, como ya se mencionó.

Para finalizar, de acuerdo a la información del Informe del Latinobarómetro (2010) la polarización izquierda/derecha de la población ecuatoriana se define el 50\% como de centro, el 8\% como de izquierda y el $10 \%$ como de derecha. Un alto $23 \%$ no se ubica en ninguna parte el espectro político y el $9 \%$ no contesta. La combinación del centro y la izquierda fue la que permitió el triunfo de un candidato presidencial considerado de izquierda en el año 2006, 2009 y 2013 con el $56 \%, 52 \%$ y $57,69 \%$ de los votos, respectivamente. Esta tendencia la menciono porque, en esta coyuntura, Pachakutik debe necesariamente negociar con el centro y la izquierda política para poder mantener su influencia y sus planteamientos. Las tesis políticas de carácter meramente étnicas han topado fondo en la sociedad ecuatoriana y se requiere una 
nueva propuesta más inclusiva donde las reivindicaciones económicas encaminadas a la equidad deben ir de la mano de las reivindicaciones dirigidas a superar la exclusión por motivos étnicos y culturales.

\section{Siglas y abreviaturas}

CODENPE: Consejo de Desarrollo de las Nacionalidades y Pueblos del Ecuador

CONAIE: Confederación de Nacionalidades Indígenas del Ecuador CONFENIAE: Confederación de Nacionalidades Indígenas de la Amazonia Ecuatoriana

CTI: Circunscripción Territorial Indígena

DINAPIN: Dirección Nacional de Pueblos Indígenas (Defensoría del Pueblo)

DINEIB: Dirección Nacional de Educación Intercultural Bilingüe

FODEPI: Fondo de Desarrollo de los Pueblos Indígenas

FEINE: Federación Ecuatoriana de Indígenas Evangélicos

FENOCIN: Federación Nacional de Organizaciones Campesinas, Negras e Indígenas

TCO: Tierras Comunitarias de Origen

\section{Bibliografía}

Báez, Sara y Víctor Bretón (2006). "El enigma del voto étnico o las tribulaciones del movimiento indígena: Reflexiones sobre los resultados de la primera vuelta electoral (2006) en las provincias de la sierra”. En Ecuador Debate N. ${ }^{\circ}$ 69: 37-50.

Burbano de Lara, Felipe (comp.) (2004). Democracia, Gobernabilidady Cultura Política. Quito: Ediciones FLACSO -Sede Ecuador.

CONAIE (2003). Políticas para el Plan de Gobierno Nacional. El mandato de la CONAIE. Quito: CONAIE. 
CONAIE (1994). Proyecto Politico de las nacionalidades y Pueblos del Ecuador. Texto aprobado por el IV Congreso de la CONAIE. Quito. Cotarelo, Ramón (1995). Los Partidos Politicos. Madrid: Sistema.

Díaz-Polanco, Héctor y Consuelo Sánchez (2002). México diverso. El debate por la autonomía. México: Siglo XXI.

Dietz, Henry and David Myers (2001). “The Process of Party System Collapse: Peru and Venezuela Compared”. Paper prepared for presentation at the 2001 Congress of the Latin American Studies Association. Washington, DC, sept. 6-8.

Freidenberg, Flavia y Manuel Alcántara (2001). Los Dueños del Poder. Los partidos politicos en Ecuador (1978-2000). Quito: Ediciones FLACSO -Sede Ecuador.

García Fernando (2001). “¿Un levantamiento indígena más? A propósito de los sucesos de febrero de 2001", en Iconos, N. ${ }^{\circ}$ 10: 3438. Quito: FLACSO -Sede Ecuador

García, Fernando y Lourdes Tibán (2008). "Entre la oposición y el enfrentamiento al diálogo y las alianzas: la experiencia de la $\mathrm{CO}$ NAIE y el MICC en Ecuador". En Gobernar (en) la Diversidad: experiencias indígenas en América Latina. Xochitl Leyva, Araceli Burguete y Shanoo Speed (ed.): 271-304. Ecuador, México y Guatemala: Ediciones CIESAS-FLACSO.

Levitsky, Steven and Maxwell A. Cameron (2001). "Democracy without Parties? Political Parties and Regime Collapse in Fujimori's Peru”. Paper prepared for presentation at the Congress of the Latin American Studies Association. Washington, DC. Sept. 6-8.

Mainwaring, Scott and Timothy Scully (ed.) (1995). Building Democratic Institutions: Party Systems in Latin America. Stanford: Stanford University Press.

Mejía, Andrés (2002). Gobernabilidad Democrática. Sistema electoral, partidos politicos y pugna de poderes en Ecuador: 1978-1998. Quito: Fundación Konrad Adenauer.

Mijeski, Kenneth J. y Scott H. Beck (2008). “The electoral fortunes of Ecuador's Pachakutik Party: the fracas of the 2006 presidential 
elections". En Southeastern Council on Latin American Studies and Wiley Periodicals, Inc: 41-59.

Mijeski, Kenneth J. y Scott H. Beck (2006). "The indigenous vote en Ecuador's 2002 presidenetial election". En Latin American and Caribbean Ethnic Studies, Vol.1, N.o 2: 165-184.

- (2004). "Ecuador's Indians in the 1996 and 1998 elections: assessing Pachakutik's performance". En The Latin Americanist, Winter/Spring: 46-76.

(2001). "Barricades and ballots: Ecuador's Indians and the Pachakutik political movement". En Ecuadorian Studies, N. ${ }^{\circ} 1$. (2000). "Indigena self-identity in Ecuador and the rejection of mestizaje". En Latin American Research Review, Vol. 35, N. ${ }^{\circ}$ 1: 119-137.

Pachano, Simón (1998). La Representación Caótica. Quito: Ediciones FLACSO-Konrad Adenauer.

Q'uellkaj Fundación (2005). Observación Electoral Intercultural, elecciones seccionales Ecuador 2004. Quito: Ediciones Q'ellkaj. (2006). Observación Electoral Intercultural, elecciones 2006, Vigilancia y cumplimiento de los derechos colectivo. Informe sin publicar. Quito.

Roberts, Kenneth (2002). "Party--Society Linkages and Democratic Representation in Latin America". En Canadian Journal of Latin American and Caribbean Studies, 27, Issue 53: 9-34.

Romero, Aníbal (1994). Decadencia y crisis de la democracia. Caracas: Editorial Panapo.

Rospigliosi, Fernando (1995). "La amenaza de la "Fujimorización" gobernabilidad y democracia en condiciones adversas: Perú y los países andinos". En Partidos y clase politica en América Latina en los 90. Carina Perelli, Sonia Picado S. y Daniel Zovatto (comp): 311-33. San José, CR: IIDH.

Tanaka, Martin (1998). "Los espejismos de la democracia: El colapso del sistema de partidos en el Perú, 1980-1995”. En Perspectiva comparada. Lima: Instituto de Estudios Peruanos. 
Van Cott, Donna Lee (2005). From Movements to Parties in Latin American: the evolution of ethnic politics. Cambridge: Cambridge University Press.

Whitehead, Laurence (2001). "High Anxiety in the Andes. Bolivia and the Viability of Democracy". En Journal of Democracy, 12, Issue 2 : 6-16.

Normativa y documentos oficiales

Constitución de la República del Ecuador (1998). Asamblea Nacional Constituyente. Quito. Decreto Legislativo N.o 000.

Constitución de la República de Ecuador (2008). Asamblea Constituyente. Ciudad Alfaro.

Congreso Nacional (2005). Código del Trabajo. Suplemento R.O. 167 del 16 de diciembre (Disponible en: http://www.ecuadorlegalonline. com/laboral/codigo-de-trabajo/).

Consejo Nacional Electoral (2013). Procesos Electorales (Disponible en resultados.cne.gob.ec/Results.html?RaceID=1\&UnitI$\mathrm{D}=1 \& \mathrm{IsPS}=0$ \&LangID=0).

Entrevistas y bases de datos

Entrevista Luis Macas (2005).

Entrevista Luis Maldonado (2005).

Latinobarometro (2010). Disponible en /www.oas.org/en/ser/dia/outreach/docs/Informe Latinobarometro Cooperacion_en_America_ Latina[1] 2010.pdf. 